\title{
NARRATIVE INQUIRY INSIGHTS: RURAL NURSE RESPONSES TO DECADES OF CHANGE
}

\author{
Jean Ross and Josie Crawley
}

\section{INTRODUCTION}

In this paper we shine light on rural nurses' innovative practice. Narrative interviews with rural nurses who practiced throughout the previous three decades provide a rich source of evidence to illustrate responsive practice against a changing political health-care landscape.

The New Zealand health-care system has been subject to major reform over the past three decades. These reforms have influenced the provision of health-care, especially in the rural regions. In response to these reforms, the funding structure for the provision of health-care services changed significantly, from a national emphasis to local rural governance. As local governance developed, so did local responses. Rural nurses were in a unique position to instigate equitable health services; during the last 30 years, many of these practices have become national norms, celebrated as New Zealand's health story.

It is timely to recognise these rural nurse pioneers. From their innovative practice emerged the contemporary identity of the nurse practising in the rural context, combining multiple traditional occupational identities as the rural nurse or rural nurse specialist.

\section{BACKGROUND}

Rural nurse stories illuminate both the minutiae and the context of rural nursing in New Zealand. Capturing their stories has helped us learn how communities and nurses have adapted to the changing socio-political, economic and health-care environment. In this paper we share our narrative inquiry insights, capturing and illustrating the creative responses of rural New Zealand nurses to shifting resources and realities.

Rural nurses service the rural population within their geographical home. Thus their community stories of practice are embedded in whenua [the sustaining land], and the use of photographic images strengthens the importance of the land to each nurse's story while recognising and honouring the connectedness of people and place. In 2018 , Stories of Nursing in Rural Aotearoa: A Landscape of Care was published (Ross \& Crawley). The book forms a treasure trove of rural nurse experiences as a testament to their dedicated practice, creativity and gritty determination. The stories draw on contributions by rural nurses throughout the whole of rural New Zealand (Aotearoa) - the North (Te Ika à Māui) and South Islands (Te Waipounamu) including the West and East coasts, as well as her offshore islands, Great Barrier Island (Aotea), Chaltham and Pitt Islands (Rēkohu/Wharekauri) and Stewart Island (Rakiura) (Figure I) - while showcasing the historical development of rural nursing practice during a time of major change, transitioning from a loosely to a highly regulated professional environment. 


\section{METHODOLOGY}

This narrative research project took place over a three-year period (2015-2018) and was divided into three phases. Funding was in the form of a research grant from Otago Polytechnic, Dunedin, New Zealand, to conduct all three phases of the project. Phase one and two addressed a gap in the literature by seeking to identify and strengthen awareness of rural nurses' changing professional practice, as well as increasing rural nurses' own understanding and articulation of it. In these initial phases, relationships with potential contributors were established at the national workshop for rural nurses, aligned with the Rural General Practice Network conference in 2016. During 2017 (phase two), fieldwork was undertaken to capture rural nurses' stories, which included images the nurses chose to include to further represent their practice. Phase three was undertaken in 2017-2018 and was divided into two parts: the first was concerned with developing the unique stories contributed by the nurses, and the second with the edited book.

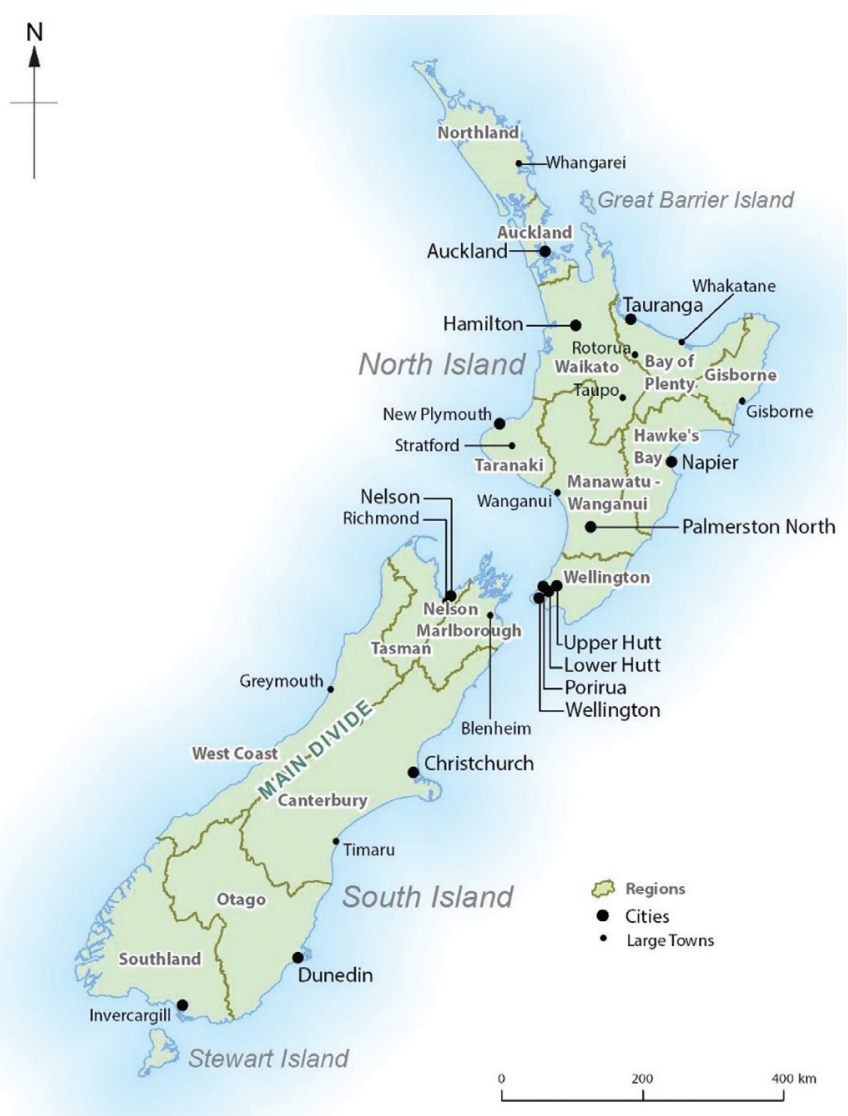

Figure I. Map of Aotearoa, New Zealand. Source: Created and published with permission from Chris Garden.

Ethical approval was obtained from the Otago Polytechnic Research Ethics Committee in 2016 including Kaitohutohu consultation and engagement. The Kaitohutohu office at Otago Polytechnic upholds the mana of the partnership with the local Mãori community, and is consulted from the research development phase, looking at proposed research from a Māori kaupapa (knowledge/overview/policy) point of view.

We were aware that our research was likely to involve Māori (the indigenous population of New Zealand) as there are a higher number of Registered Nurses who identify as Māori in the rural practice setting ( $N=59 ; 11.6 \%)$, compared to 6.5 percent in the overall workforce (Nursing Council of New Zealand, 20 I5). Statistics show that 14 percent of the New Zealand population is Māori; over three quarters of the Māori population live outside the Auckland urban area, making up a significant part of the nation's rural communities (Statistics New Zealand, 20I3). Rural nursing is a valued setting for Māori Registered Nurses' employment, and nurses' practice stories potentially include reference to tikanga Māori (customs, values and practices) within the context of describing their work. 


\section{PARTICIPANTS}

Invitations to rural nurses from New Zealand to participate in the project were canvassed through email contacts, newsletters, national nursing journals, regional directories and websites and through professional networks. The criteria included being in rural practice for more than 15 years, as this ensured that those participating had practised in the country's changing socio-political and economic health-care context (discussed further below). These criteria reduced participants from an initial 58 expressions of interest to 40 potential participants who met the research criteria, of whom 25 were in a position to commit to the project's requirements and time frames.

Of the 25 stories originally gathered, 16 were subsequently edited and reworked by both the participant and the researcher for sharing in the book. Each nurse storyteller featured in the book is identifiable; there is no anonymity. We ensured that we did not hurry or coerce participants, so that they could consult with their own community and whanau (family). The open, semi-structured interviews used respect each story as it is told. Each is framed by a structure (shared pre-interview) - a "three-dimensional narrative enquiry space" which includes the past, present and future, and situation and place, as well as personal and social elements experienced by both the researcher and the participant (Clandinin \& Connelly, 1998). This framework was sufficiently flexible to encompass the influence of time, whenua and tikanga within each story told. Future details of the model are given below.

\section{NARRATIVE INQUIRY}

Ever since humans have been able to communicate in gestures and ink, stories and pictures have been a way of making sense of the world. The world we live in and the institutions we work in form an interconnected web of narratives, with stories of the past shaping our present (Clandinin, 2013; Crawley, 2009). Research has recognised the power the story has to explore meaning, make connections, to entertain, build empathy and to teach, with benefits for both receiver and teller (Haven, 2007). Based on the solid foundation of the study of narrative, since the 1990s a methodology that characterises narrative as both a phenomenon and a research methodology has been known as narrative inquiry - "a way of understanding and inquiring into experience" (Clandinin, 20 I3, p. I3).

Research based on narrative inquiry was used to collect the 16 stories published in the book. This is a qualitative methodology - story is the medium used to explore the structured phenomenon of rural nursing in New Zealand, as lived and told by experienced nurses. The personal and human dimensions triumph over statistics, as the in-depth meaning of their experience was described by each individual storyteller. Each rural nurse involved was an active participant in the research, deconstructing dominant 'truths' against stories of personal experience, checking and rechecking that their story reflected what they wanted to tell. Each participant was invited to send photographs to supplement their story in the published book. In health humanities, images can distil meaning (act as symbols), both for the person taking the image and for the person viewing it (Crawford, Brown, Baker, Tischler, \& Abrams, 20I5). The photographs add visual depth to the text, and offer an alternative interpretation for viewer and storyteller alike.

The participants' stories used a personal and social lens to explore the past, the present and the future of the rural nurse journey, capturing the essence of place, distance, historical change and both the joys and challenges of working embedded in a variety of rural communities. Their personal perceptions, life experiences, their community, their values and the physical geography of the places where they work together shape each unfolding story. To capture and share the stories of New Zealand rural nurses, we wanted to ensure that the voices heard are theirs (although it is also important to acknowledge the contribution of the researcher).

Clandinin (2013) describes narrative inquiry as a relational methodology. The researcher intentionally relates to participants and, as inquirers, we consider our own experiences as well as those of the participants. As inquirers, we influence the phenomena being studied, as we temporarily become part of the participants' landscapes. Given the narrative paradigm, the authors were in the privileged position of collecting and editing the stories. Each of the 16 stories published involved contacting the storyteller, arranging a time and venue and a vector for sharing and 
recording their story. Each story was guided by Clandinin and Connelly's (1998) "three-dimensional narrative inquiry space" - a model that examines personal and social interactions across the continuity of time and context. The use of this framework by all interviewers (as a way of reducing researcher bias), and a preview of the framework by interviewees, provided a thematic but open structure of past, present and future responses to the challenges faced - whether political, financial, geographical or demographic. As interviewers and narrative researchers, we were listening, clarifying, reading transcripts, editing, discussing, rereading and editing again at least three more times. These rural nurse stories were what Clandinin (2013) describes as "co-composed in the spaces between us as inquirers and participants" (p. 24).

Clandinin (20 I3) describes how for narrative inquirers, participants' experiences become visible as we walk alongside their stories and their contexts. As narrative researchers, our familiarity with the 16 stories, ongoing communication with the participants, our fieldwork meetings and shared process to ensure consistency in collecting and editing the stories produced a resounding shared insight: the last 30 years of rural nurse practice in New Zealand have been full of pioneering responses to a changing environment, responses that have shaped New Zealand's current health context.

\section{DISCUSSION}

The effects of the economic downturn of the global market during the 1980s and 1990s had a dramatic effect on the health-care system in New Zealand as well as health-care practitioners, including nurses, particularly rural nurses. With limited funds at its disposal, the government enacted major health reforms, resulting in changes to the provision of health-care (Hounsell, 1992; Prince, et al., 2006) and changes in the delivery, funding, governance structures (National Health Committee, 20I0; Dalziel \& Saunders, 20I4) and models of health-care (Carryer et al., 20 I5). The government's aim was to increase efficiency and address the needs resulting from increasing health disparities while providing health-care in the most fiscally prudent way (Barnett \& Barnett, 2009).

This restructuring was influenced by neo-liberal political philosophy (Barnett \& Barnett, 2009). The neo-liberal reforms emerged towards the end of the twentieth century and reduced the responsibility of the state and the welfare sector to the individual and, in so doing, increased competition among health-care practitioners and service providers (Prince et al., 2006).

Rural communities across New Zealand/Aotearoa responded to the changing health environment and fluctuating funding levels with a variety of models designed to meet the health needs of their local communities. The changing needs of these communities have continued to be apparent, in parallel with a changing health-care context. Rural nurses put a stake in the ground with the aim of responding to these changes and enabling equity - exploring new practice models to ensure that the best levels of health-care were available (as we share in this paper).

The rural nurses we interviewed revealed the practice models they adopted in response to these changes. Firstly, nurses had the opportunity to purchase and govern general practices, which were traditionally owned and operated solely by general practitioners (GPs) - those with a medical background. Nurse Kim Carter became a practice owner in rural Canterbury. She explains that while influencing the outcome of the provision of health-care in her district,"I have the added element that this organisation is very much reflecting my practice and the way we [nurses] construct our care, and how we do that in partnership with our community" (Ross \& Crawley, 20 I8, p. 55).

The establishment of Rural Community Trusts (RCTs) was one outcome of the country's major health-care reforms (Gauld, 2000; Eyre \& Gauld, 2003). Their engagement with local community members meant that RCTs designed and managed their own individual local health services; this model was regarded by the government as innovative and came with associated cost savings. The stimulus for this restructuring was the government's acknowledgment of continuing inequalities in health, in particular, in the indigenous Mãori and Pacific population (Matheson \& Neuwelt, 2013). 
As well as encouraging community involvement in health-care decision-making (Gauld, 200 I; Eyre \& Gauld, 2003), the RCTs assisted in the development of "by Māori, for Māori" iwi providers (Gauld, 2003). Leonie Howie, a rural nurse storyteller from Great Barrier Island (Figure I), discusses how Māoritanga (the Māori cultural way of life and understanding) is infused into the rhythm of island life, weaving symbiotically into the holistic approach of the rural nurse. She describes her own affiliation with Ngāti Wairere as helping her understand at a deeper level that "belonging remains at the heart" (Ross \& Crawley, 20 I 8, p. 33). Furthermore, as the Great Barrier Island Community Health Trust became established, Leonie Howie describes how a local kuia (female elder) spearheaded the island's initiative to have a "centrally located, properly equipped health centre" (Ross \& Crawley, 2018, p. 32), along with local health-care workers. After community fundraising, the community health centre was opened in 1990, and remains an active trust on Great Barrier Island to this day. The health trust is unique in that it owns all its buildings and resources, but does not contract health services.

In 1994, Aotea Health Ltd was established, providing holistic primary care to Great Barrier Island residents from antenatal to palliative care - co-directed by two nurses, Leonie Howie and Adele Robertson (Ross \& Crawley, 2018). Adele Robertson describes how being able to control both funding and decision-making provided nurses with a satisfying sense of autonomy to meet the needs of their island community: "[ [] o bring that money onto the island and then have a say about how it got spent, was very empowering. It has been an exciting journey and that is basically what has kept me here" (Ross \& Crawley, 20 I 8, p. 37).

Although RCTs were very diverse in size, their organisational arrangements and the services that they provided, they all represented a unique community strategy designed to secure health services for their individual rural areas. In the long run, all these trusts ensured the feasibility of community health services, having been redesigned to perform this function (Barnett \& Barnett, 200 I; Eyre \& Gauld, 2003). The RCTs, including nursing services, were driven by the health needs of their communities which, over time, granted rural nurses a strong community involvement while enhancing communities' social capital.

In the 1990s, with some government support, these trusts were further developed into an alternative mechanism for the ownership and continuance of health services in rural areas (Barnett \& Barnett, 2005). The trusts generally employed all local health-care staff including the GP. These new employment arrangements gave the RCTs a significant advantage over the traditional model of self-employed GPs associated with the fee-for-service payment model and the direct employment of nurses (Barnett \& Barnett, 200I). GPs' employment of practice nurses was recognised as one barrier associated with the deployment of nurses - in particular, the "practice nurse," as noted in the 1998 Ministerial Taskforce Report (Ministry of Health, 1998). Rosters shared between GPs and rural nurses covered 24 hours of health-care at the weekends and during week nights.

One noticeable difference between rural and urban nursing practice was the expectation that rural nurses would provide an emergency health-care service in the form of Primary Response in Medical Emergencies (PRIME). It is important to acknowledge this in the context of changing models of health-care and funding and the provision of sustainable health-care by rural nurses. The PRIME "service is funded by the Ministry of Health and the Accident Compensation Corporation (ACC) and is administered by St. John. It utilises the skills of speciality trained rural GPs and/or rural nurses in areas to support the ambulance service where the response time for assistance would otherwise be significant or where additional medical skills would assist with the patients' condition" (Ross \& Crawley, 2018 , p. 39).

Rural geographical locations offer different levels of isolation and support. Tania Kemp compares PRIME on the Chatham Islands and in rural South Canterbury, having practised in both locations. PRIME calls were often about rural accidents involving acute care and a high death rate - often involving cars, fishing and farming - with hospitallevel care a flight, or two to three hours' drive away. "On the Chathams and on Pitt Island you were on your own; there wasn't anybody else. ... One big difference doing PRIME in Waimate, you worked with the ambulance ... I had wheels to get us to Timaru hospital ... I had support, I had comrades..." (Ross \& Crawley, 20 18, p. 47). 
Changing governance structures meant that nurses were able to shape the direction and delivery of health-care. For the first time, chemotherapy was administered by rural nurses in selected regions. This innovative practice was later recognised by the establishment of Nurse Specialists. Like all new practices, changes were scaffolded to make innovation possible. In this case, nurses becoming intravenous-certificated was an important first step to providing local access to chemotherapy. The alternative model required local residents to travel 3-5 hours, in each direction, to an urban health-care facility. Janet Wright, a rural nurse from South Canterbury, explained that "[w]e needed to adapt, which as rural nurses we do very well. So we changed it [the delivery of chemotherapy] to more of a medical day unit and took on doing other transfusions" (Ross \& Crawley, 20 I8, p. 53).

This approach to the delivery of health-care was designed to meet the localised health needs of the community, such as in rural Northland, where one nurse described "going around delivering services in all schools to children with runny ears, glue ears, ear problems ... [and] hearing problems" (Ross \& Crawley, 20 I 8, p. 22).

Throughout the book, such pioneering stories are told one after another, displaying models of practice in response to change and to ensure that access to health-care was maintained and ultimately improved. As Tania Kemp put it:

To make it work in rural [areas], I needed to be able to do more than what the RN scope allowed me, in order to really be available for rural people.... slowly as I moved out into more rural [areas] and away from that physical support of a GP or another health colleague, the more I needed the tools to be able to be available to those patients (Ross \& Crawley, 20 8, p. 50).

From such innovative practice emerged the contemporary identity of the rural nurse, combining multiple traditional occupational identities. As local governance developed, so did local responses. Rural nurses were in a unique position to pioneer equitable health services - such as providing localised treatment and palliative care, PRIME (as discussed above), Standing Orders, Telehealth, the transfer of acute patients to tertiary bases and community mental health, as well as developing the Nurse Practitioner role and establishing community trusts (Ross \& Crawley, 20 I 8).

Shona Blair, a rural nurse from Queenstown, explained how transfer nursing worked:"I used to do a lot of ambulance work or helicopter work ... flying patients to Dunedin ... and some of that stuff was quite scary because we are in the mountains here.... So everybody who had to get out of here by helicopter were usually very sick and they needed to be treated in a larger hospital" (Ross \& Crawley, 20 I8, p. 90).

For rural nurses, being a generalist means developing expertise in many roles and juggling several contracts at once. Liz Burns, a rural nurse from the West Coast of the South Island - with a huge geographic area to cover - describes the roles she shares with a colleague:

It's really a one-stop shop.... we cover Prime, ACC, District Nursing, Public Health Nursing ... plus we do palliative care ... When the GP is here - we generally have a doctor here one morning a week - we're the Practice Nurse when they're here. ... I think it's a privileged position, rural nursing. ... It really sort of stops and starts with us. In saying that, we have an amazing team behind us [respiratory nurse specialists, diabetic nurse specialists, cardiac nurses, palliative care teams and oncology nurses, GPs, physios and Occupational Therapists]. Nobody stands alone (Ross \& Crawley, 20।8, p. 76).

Nurses working in rural hospitals also had to have generalist specialist skills to meet the needs of the community, given limited resources. Dianne Pollard, another West Coast nurse, explains how the small four-bed critical care unit she works in, as a sole nurse on eight-hour shifts, also functions as the medical and surgical high-dependency unit, the coronary care unit and the intensive care unit - providing expertise to paediatric (children) and adult patients, both in the critical care unit and, if necessary on the wards. She is also on the voluntary roster for ventilator call (assistance with breathing), averaging around three shifts a week after hours.

Helen Sawyer, also from the West Coast of the South Island, describes how the rural nurse role expanded as services closed during the 1990s and 2000s: 
[O] ur theatre closed, meaning all surgery cases were attended to in Greymouth (two hours' drive). We lost our generalist surgeon and anaesthetist. A lot of our services were cut down and they started doing visiting clinics for follow ups to save people going down after their appointments. We learned to do what we were able, and that involved a lot of travelling in ambulances, bringing patients to the ward to stabilise, then we'd transfer them ... you have to be a generalised specialist in all fields. You are triaging patients as they present (this can be from a non-event to life-threatening trauma ...), delegating tasks, liaising with the doctor, arranging transport, communicating with other areas' transport [prioritising], hand-over of patients and notifying or liaising with the family (Ross \& Crawley, 20 I8, p. 63).

With this expansion of practice came the rural nurses' need for ongoing and advanced education. Postgraduate education for rural nurses was established in 1998 (Ross, 2016; Maw, 2008) and funded by the Clinical Training Agency (CTA). It became a priority following a study commissioned by the Southern Regional Health Authority in 1995 which sought to understand the evolving role of the rural practice nurse in the South Island (Ross, 1996; Thompson, 2006; Maw, 2008).

In their stories, the rural nurses talked about completing postgraduate studies, gently dipping their toe into the water to experience this form of advanced education. According to Gaylene Hastie, a rural nurse practitioner from Queenstown in Central Otago, many rural nurses got hooked. She said that postgraduate education "sparked my interest in postgraduate study where I was becoming aware of the theory behind practice, how to sustain nursing practice, [the] context of communities and how this guides our nursing practice. I got a taste of what postgraduate education could offer and the journey had begun" (Ross \& Crawley, 2018, p. 94).

Nurse leaders from New Zealand ensured that a statement relating to the practice of nursing was included in the development of the philosophy behind the government's Primary Health-care Strategy (Ministry of Health, 200 I), which promotes Primary Health-care (PHC) nurses as central to the delivery of care in the community. For nurses to practise in the context of PHC philosophy, a shift in thinking by nurses and educators alike was necessary to ensure that nurses could acquire the skills necessary for autonomous practice and guarantee that they would be in a strong position to practise in the community. Practising in the community required nurses to focus on wellness and health promotion and to provide education to individuals and groups within the framework of PHC nursing.

The PHC philosophy understands health in social terms - health is associated with social inequalities, community engagement and the participation and empowerment of individuals and communities (Duncan et al., 20l4). Communities in rural areas often pull together to provide what they think is necessary - the level of community engagement and participation is strong, even in some of the country's most economically deprived rural areas. This might involve fundraising for new clinics, hospitals and resources; providing options for clients without transport; providing food parcels for families when nurses are away doing further training; volunteering to assist in emergency response situations; being the driver for an exhausted on-call nurse; or being creative in ensuring that services are delivered where they are needed (Ross \& Crawley, 2018). According to Liz Burns,

I know health-care's got to be paid for, but when I first started, nobody paid for anything. Now basically everybody pays for everything, except for District and Public Health Nursing. Some people just can't pay - but they need to be seen ... And they can't afford to go to the GP, they can't afford to pay for their antibiotics ... I don't think we should be creating dependents - but with just very little you can really make a change with people and help them move forward and on (Ross \& Crawley, 2018, p. 77).

Sometimes the assistance given is very practical. Adele Robertson recollects one client who would not leave Great Barrier for rehabilitation until he had a return ticket in his hand. While he was gone, his neighbours held a working bee to adapt his multi-level home, creating railed access so that the client had every chance of ending his life at home, as he wished (Ross \& Crawley, 2018) - a fine illustration of an empowered individual within an engaged community. Tania Kemp knows that her practice has the absolute support of the community. "Lions Club are buying 
us a defibrillator ... A local school say 'Hey, do you want to use us?' [for an evacuation plan in emergencies]There's no such thing as having to go begging and saying 'can we do this and this?' People are so supportive of you in a small community" (Ross \& Crawley 2018, p. 48).

It is clear that rural nurses are part of their community, above and beyond their nursing role. The rural nurses' stories collected in this project have revealed the extent of nurses' work with allied health organisations such as St Johns - becoming members of the local St Johns committee and training to be an ambulance officer to further support the community and their health needs (Ross \& Crawley, 20I8). Teamwork is essential.

The rural nurses acknowledged that working in teams creates an environment in which specialist skills and knowledge can be shared, enhancing collaborative work to provide a wide range of services in an efficient manner - an experience that is supportive and also fun (Ross \& Crawley, 2018). Supportive teamwork and dedication to the community can mean some very long hours, where both the team and the local community work to support each other, whether in the rural hospital or in the community.

West Coast nurse Julie Lucas describes receiving a phone call saying a STAT I (life-threatening, requiring resuscitation) patient was coming in. The ambulance driver knew the patient was Julie's father, so rang Julie's off-base manager, who promptly returned to relieve and support her (Ross \& Crawley, 20 I 8). Later in her story, Julie notices an emergency on her way home, and returns to work to support an inexperienced colleague. On the West Coast, rural hospitals (and allied resources) and rural nurses work together as much as possible - they are part of the same team. Julie Lucas says that, in her community, they "rely on a lot of nurses stepping up into different specialities (like Rural Nurse Specialists, Nurse Practitioners, Clinical Nurse Specialists), because it is very difficult to retain doctors in a lot of those areas [the remote West Coast] ... They have to work in that community alone, although they do get support by ringing our emergency department... (Ross \& Crawley, 2018, p. 72).

The community is also part of this team. Liz Burns chooses to cross over with her colleague, doing a half-day handover - necessary after a self-chosen schedule of seven and half days on duty and six days off." When you are looking at what you can do, you actually have to consider the fact that you only have one pair of hands, no one else is there" (Ross \& Crawley, 2018, p. 75). Her rural West Coast district is one of the few mainland areas with no ambulance back-up, and often no cell reception. The local fire brigade is being upskilled by St Johns, eventually becoming part of the first response team. Because the fire brigade is at least an hour closer to the community than an ambulance, the rural nurse educates them twice a year to ensure the brigade knows everything that is packed into the nurses' car, and is able to fetch things as needed. Here, the community expects to be part of the team, and responds to the nurses' needs - Liz Burns reports that the local community had just fundraised to build a new health clinic.

Involving community members in setting their own health needs was a significant shift in philosophy, going beyond anything that had been attempted previously. The aim was to reduce health disparities while being true to the principles of $\mathrm{PHC}$, which encouraged working from the bottom up (at the grassroots) and minimised a top-down (government-directed) approach in the implementation of health-care (Neuwelt \& Crampton, 2005; Matheson \& Neuwelt, 20 I3). At this time, the health-care system was transformed by situating PHC at the centre of health-care, while also considering nursing as crucial to its success (Ministry of Health, 200 I). This philosophy is encapsulated in the words of Martinius Pepers, a rural nurse on Stewart Island (the southernmost inhabitated area of New Zealand; see Figure I), who expresses his practice as

becoming an expert in all facets of clinical presentations of all times of the day and night. This has required me to be practical, adaptable and flexible and engage in the community. As I have engaged in the community I have developed as an individual, taking responsibility for community issues, health issues and environmental concerns. I would say I am fulfilled and I hope I fulfil this community's needs as well (Ross \& Crawley, 2018, p. 107). 
This account of the varied and interesting work carried out by rural nurses is a synopsis to be shared and is a component of our ongoing work. The raw data from interviews with 25 rural nurses is currently undergoing thematic analysis in order to generate further knowledge of rural nursing practice and curriculum development, as well as professional development intended to equip rural nurses for the varied demands of their practice. Our research will also inform workforce planning, with the aim of improving the recruitment and retention of rural nurses. We envisage that this will further open up ideas for the contributions that rural nursing will be able to make in the future, thereby adding to the growing national and international research in this area.

\section{CONCLUSION}

Narrative inquiry has been used to celebrate and share the lived experiences of New Zealand rural nurses, while showcasing how they have adapted their practice over the last few decades. Their stories illustrate creative responses to a changing health environment, with innovative responses to a variety of challenges strongly evident. During the last 30 years, many of the practices described in their stories have become national norms, celebrated as part of New Zealand's health story; it is timely to recognise these rural nurse pioneers. Capturing these stories has helped us learn how nurses have adapted to the changing socio-political and economic environment, while identifying rural nursing as a specialty area of nursing practice.

In 2019, rural nursing is still not officially identified as a separate specialty of nursing practice in New Zealand, and this lack of identity has often left this occupational group misunderstood and challenged by the wider nursing profession and the policies governing nursing practice. In this paper, we have outlined the research project we have undertaken and the book we have published to demonstrate why and how rural nursing should be recognised as a speciality area of nursing practice which is comparable internationally. Rural nurses service the rural population within their geographical home; thus their stories of practice are embedded in whenua, underlining the importance of the land to each rural nurse's story while recognising and honouring the connectedness of people. As we celebrate these stories, our chief remaining aim is to strengthen the position of rural nursing, both nationally and internationally.

Associate Professor Jean Ross (미 0000-0003-2467-9233) RN, Bn, MA Nursing, PhD, FCNA (NZ) is Associate Professor in Nursing at Otago Polytechnic, Dunedin, New Zealand. She has more than 25 years' experience of working with the rural nursing workforce. The cumulation of her work associated with rural nursing, includes research and education. Jean's initial work with rural nurses commenced in 1994 with the establishment of the setting up of the National Centre for Rural Health in New Zealand of which she was co-director. Jean has published 2 books and numerous journal publications. She is passionate about community development and is the co-editor of Stories of Nursing in Rural Aotearoa: A Landscape of Care.

Josephine Crawley (마 0000-0003- I0 I I-3335), RN, BA, Med, GCTLT Josie is a Principal Lecturer at the School of Nursing, Otago Polytechnic. She has been involved in nurse education in both the community and institutions for over 25 years. Her research platform explores the place of narratives within nursing education for reflection, to build compassionate care and to research the client and nurse experience. She has published in a variety of academic journals, case studies, presented internationally, and her poetry has been included in a collection of poems by Aotearoa New Zealand Nurses. She is passionate about health promotion and is the co-editor of Stories of Nursing in Rural Aotearoa: A Landscape of Care.

Correspondence to: Jean Ross, Otago Polytechnic, Dunedin, New Zealand. Email: jean.ross@op.ac.nz 


\section{REFERENCES}

Barnett, P., \& Barnett, J. R. (200 I). Community venture in rural health:The establishment of community health trusts in southern New Zealand. Australian Journal of Rural Health, 9(5), 229-234.

Barnett, P., \& Barnett, J. R. (2005). Reform and change in health service provision. In P. Davis \& K. Dew (Eds.), Health and society in Aotearoa New Zealand (2nd ed., pp. 178-193). Auckland, New Zealand: Oxford University Press.

Barnett, J. R., \& Barnett, P. (2009). Reinventing primary health care:The New Zealand case compared. In V.A. Crooks \& G. J.Andrews (Eds.), Primary health care: People, practice, place (pp. 149-165). Farnham, England: Ashgate.

Carryer, J., Halcomb, E., \& Davidson, P. M. (20I5). Nursing the answer to primary health care. Collegion, 22(2), I5I-I52.

Clandidin, J., \& Connelly, M. (1998). Narrative inquiry: Experience and story in qualitative research. San Francisco, CA: Jossey-Boss.

Clandinin, J. (2013). Engaging in narrative inquiry. New York, NY: Routledge

Crawford, P., Brown, B., Baker, C., Tischler,V., \& Abrams, B. (20I5). Health humanities. Basingstoke, England: Palgrave Macmillan.

Crawley, J. M. (2009). "Once upon a time": A discussion of children's picture books as a narrative education tool for nursing students. Journal of Nursing Education, 46(I), 36-39.

Dalziel, P., \& Saunders, C. (20।4). Wellbeing economics: Future directions for New Zealand. Wellington, New Zealand: Bridget Williams Books Publishing Trust with the G \& NTrust.

Eyre, R., \& Gauld, R. (2003). Community participation in a rural community health trust:The case of Lawrence, New Zealand. Health Promotion International, 18(3), I89-197.

Garden, Chris. (2016). Map of New Zealand. Department of Geography, University of Otago, Dunedin, New Zealand.

Gauld, R. (200 I). Revolving doors: New Zealand's health reforms. Wellington, New Zealand: Institute of Policy Studies, Victoria University.

Haven, K. F. (2007). Storyproof: The science behind the startling power of the story. Westport, Connecticut: Libraries Unlimited.

Hounsell, D. (1992). The collegial relationship: Practice nurse and general practitioner. New Zealand Practice Nurse, Dec, 40-4 I

Hutton, G. (20|6). Models of care as it applies to South Westland. Paper presented at the National Rural Health Conference,Wai Ora, Healthy Environments, Dunedin, New Zealand. New Zealand Rural General Practice Network.

Matherson, D., \& Neuwelt, P. (20I3). New Zealand's journey towards people-centred care. The International Journal of Person Centred Medicine, 2(I), 73-79.

Maw, H. (2008). The challenge of developing primary health care nurse practitioner roles in rural New Zealand. In J. Ross (Ed.), Rural nursing: Aspects of practice (pp. 20I-214). Dunedin, New Zealand: Rural Health Opportunities.

Ministry of Health (1998). Report of the ministerial taskforce on nursing. Wellington, New Zealand: Author.

National Health Committee (20 10). Rural health: Challenges of distance opportunities for innovation. Wellington, New Zealand: Author.

Neuwelt, P., \& Crampton, P. (2005). Community participation in primary healthcare in Aotearoa New Zealand. In K. Dew and P.Davis (Eds.), Health and society in Aotearoa New Zealand (pp. 194-210). Melbourne, Australia: Oxford University Press.

Prince, R., Kearns, R., \&, Craig, D. (2006). Governmentality, discourse and space in the New Zealand health care system, 199 I-2003. Health \& Place, 12, 253-66.

Thompson, L. E. (2006). Profession and place: Contesting professional boundaries at the margins (Unpublished PhD thesis). University of Canterbury, Christchurch, New Zealand.

Ross, J. (2016). Place matters to rural nurses. (Unpublished PhD thesis). Department of Geography, University of Otago, Dunedin, New Zealand.

Ross, J., \& Crawley, J. (Eds.). (20।8). Stories of nursing in rural Aotearoa: A landscape of care. Dunedin, New Zealand: Rural Health Opportunities. 